\title{
Intercomparison of the Charnock and COARE bulk wind stress formulations for coastal ocean modelling
}

\author{
J. M. Brown ${ }^{1}$, L. O. Amoudry ${ }^{1}$, F. M. Mercier ${ }^{1,2}$, and A. J. Souza ${ }^{1}$ \\ ${ }^{1}$ National Oceanography Centre, Joseph Proudman Building, 6 Brownlow Street, Liverpool, L3 5DA, UK \\ ${ }^{2}$ Ecole Centrale de Lyon, 36 avenue Guy de Collongue, 69134 Ecully Cedex, France \\ Correspondence to: J. M. Brown (jebro@noc.ac.uk)
}

Received: 14 February 2013 - Published in Ocean Sci. Discuss.: 8 March 2013

Revised: 28 June 2013 - Accepted: 2 July 2013 - Published: 14 August 2013

\begin{abstract}
The accurate parameterisation of momentum and heat transfer across the air-sea interface is vital for realistic simulation of the atmosphere-ocean system. In most modelling applications accurate representation of the wind stress is required to numerically reproduce surge, coastal ocean circulation, surface waves, turbulence and mixing. Different formulations can be implemented and impact the accuracy of the instantaneous and long-term residual circulation, the surface mixed layer, and the generation of wave-surge conditions. This, in turn, affects predictions of storm impact, sediment pathways, and coastal resilience to climate change. The specific numerical formulation needs careful selection to ensure the accuracy of the simulation. Two wind stress parameterisations widely used in the ocean circulation and the storm surge communities respectively are studied with focus on an application to the NW region of the UK. Modelobservation validation is performed at two nearshore and one estuarine ADCP (acoustic Doppler current profiler) stations in Liverpool Bay, a hypertidal region of freshwater influence (ROFI) with vast intertidal areas. The period of study covers both calm and extreme conditions to test the robustness of the $10 \mathrm{~m}$ wind stress component of the Coupled OceanAtmosphere Response Experiment (COARE) bulk formulae and the standard Charnock relation. In this coastal application a realistic barotropic-baroclinic simulation of the circulation and surge elevation is set-up, demonstrating greater accuracy occurs when using the Charnock relation, with a constant Charnock coefficient of 0.0185 , for surface wind stress during this one month period.
\end{abstract}

\section{Introduction}

For realistic simulation of the atmosphere-ocean system an accurate parameterisation of momentum and heat transfer across the air-sea interface is required. Coupled modelling systems are often used to include interactions across this boundary (e.g. Liu et al., 2011). In oceanographic applications the parameterisation of the surface roughness is very important. The presence of waves can influence the coastal circulation and also sea surface temperatures through modification of the surface turbulence and mixed layer depth (Moon, 2005). The presence of ocean surface waves also modifies the wind profile itself (Large et al., 1995), requiring ocean-atmosphere model coupling to capture the feedback (Kukulka and Hara, 2008). Climate variability is also influenced by ocean-atmosphere interaction; model coupling is therefore essential to better understand the global climate and future change (Neelin et al., 1994). In barotropic storm surge models the wind stress is often represented by the Charnock (1955) relation between the wind speed and the surface roughness. In coupled wave-circulation models this parameterisation is often extended with a wave-related stress (Janssen, 1991) to properly account for the existence of the wave field (see Mastenbroek et al., 1992). In noncoupled ocean models it is common to apply bulk formulae to atmospheric forcing fields to determine surface fluxes for baroclinic-barotropic circulation studies (e.g. Holt and Proctor, 2008). In the absence of ocean-atmosphere coupling the implementation of different formulations can impact the accuracy of the instantaneous and long-term residual circulation, and also the generation of coastal wave-surge conditions. This, in turn, affects predictions of storm impact, 

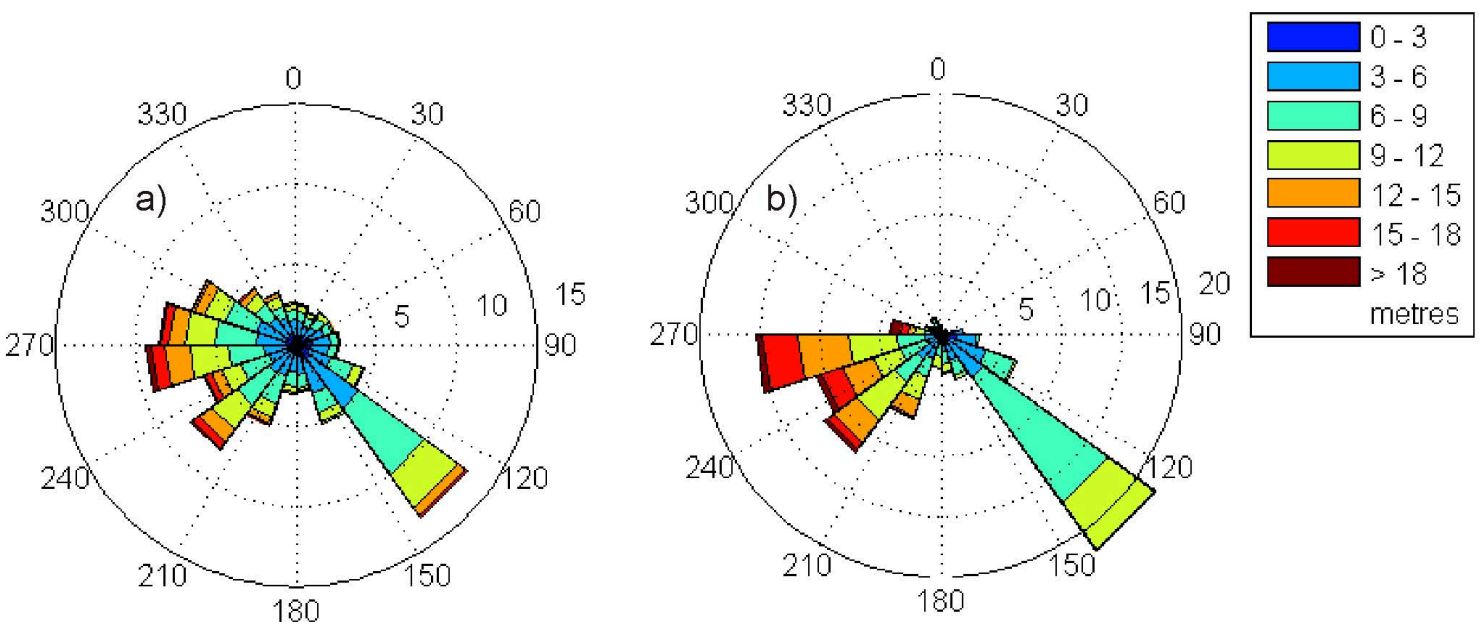

Fig. 1. Wind Roses from the Hilbre Island Met station for (a) 2005-2012 and (b) the study period.

sediment pathways, and coastal resilience to climate change. To enable the best prediction of coastal circulation, we investigate two wind stress formulae widely used in the ocean circulation and the storm surge communities. We focus on an application to Liverpool Bay, which is in the NW region of the UK and a case study of specific interest for improving the understanding of sediment pathways around the UK. At this location both the Charnock (1955) relation and the COARE (Coupled Ocean-Atmosphere Response Experiment) bulk formulae (Fairall et al., 2003) have previously been used in separate studies of storm surge extremes (Brown and Wolf, 2009) and freshwater influence (O'Neill et al., 2012), but not compared.

Model comparisons against ADCP (acoustic Doppler current profiler) data are employed at two nearshore and one estuarine location in Liverpool Bay, which is a hypertidal region of freshwater influence (ROFI) from three large estuary systems (Polton et al., 2011; Verspecht et al., 2009), and which is characterised by a maximum tidal range of approximately $10 \mathrm{~m}$, maximum currents in excess of $1 \mathrm{~ms}^{-1}$ and vast intertidal areas. The period of study (9 February9 March 2008) coincides with a period of observations within the Dee Estuary (14 February-9 March 2008, Bolaños and Souza, 2010), which are supplemented with nearshore measurements from the Liverpool Bay Coastal Observatory (COBS: http://cobs.noc.ac.uk/, Howarth and Palmer, 2011) to investigate a 30 day period. The wind characteristics during this period are dominated by southwest to westerly winds (Fig. 1). Both calm and stormy conditions, including an extreme storm event (29 February 2008), occur during this period to fully test the robustness of the following:

1. The $10 \mathrm{~m}$ wind stress component of the COARE bulk formulae used in operational barotropic-baroclinic deep ocean circulation modelling.
2. The standard Charnock relation used in operational barotropic surge modelling to capture increased surface roughness due to the presence of waves on the surface stress due to the $10 \mathrm{~m}$ wind components.

In this coastal application, a high-resolution $(\sim 180 \mathrm{~m})$ Liverpool Bay model is nested within models of decreasing resolution. This enables the Liverpool Bay boundary forcing to include the tide-surge and baroclinic influence from the northwestern European continental shelf and more locally within the Irish Sea. The full COARE bulk formulae consist of methods to parameterise a set of atmospheric variables. These include air temperature, relative humidity, cloud cover, atmospheric pressure and surface wind stress, to represent the transfer of heat and momentum fluxes across the atmosphere-ocean boundary in addition to the inverse barometer effect. This forcing along with riverine inputs allows a realistic barotropic-baroclinic simulation of the circulation within the study area. The full COARE bulk formulae (Fairall et al., 2003) are initially used to represent the complete atmospheric forcing. A second simulation then replaces the wind stress parameterisation within the COARE bulk formulae with that of the standard Charnock (1955) relation, using a constant Charnock coefficient of 0.0185 (consistent with the Irish Sea model set-up as suggested Brown and Wolf, 2009, for fine resolution models). The difference between the two wind stress parameterisations is the representation of the surface roughness length. In the COARE bulk formula a varying Charnock coefficient is applied and the Charnock roughness length is extended to include smooth surface conditions. The Charnock coefficient varies with the $10 \mathrm{~m}$ wind speed $\left(U_{10}\right)$, it is set to 0.011 for $U_{10} \leq 10 \mathrm{~m} \mathrm{~s}^{-1}$, to 0.018 for $U_{10} \geq 18 \mathrm{~m} \mathrm{~s}^{-1}$, and increases linearly for intermediate values of $U_{10}$.

In Sect. 2 the model set-up is described for Liverpool Bay along with the observed conditions during the period of study. Metrics to validate the model performance under 

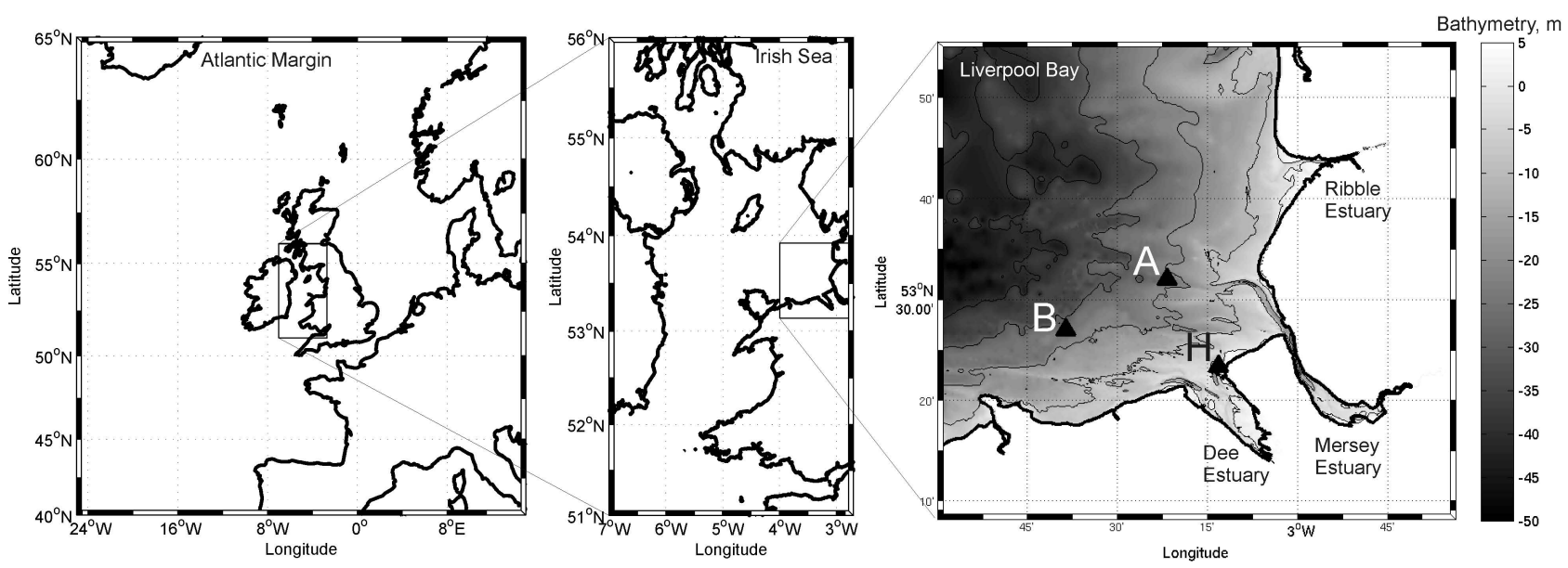

Fig. 2. The Atlantic Margin model domain (left), nested Irish Sea model domain (middle), and nested Liverpool Bay domain (right) with model bathymetry (in $\mathrm{m}$ below the mean tidal level) shown as $10 \mathrm{~m}$ contours and the mooring locations marked as triangles: Site A (A), Site B (B) and Hilbre (H).

different wind stress parameterisations are defined and used in Sect. 3 to present the results of the model accuracy. A short discussion of the results and concluding remarks are made in Sect. 4.

\section{Model set-up and observations}

This study focuses on accurately simulating the coastal circulation, currents and surge elevation, within a hypertidal region or freshwater influence (Polton et al., 2011). We apply the Proudman Oceanographic Laboratory Coastal Ocean Modelling System (POLCOMS, Holt and James, 2001) to simulate the coastal circulation within Liverpool Bay. POLCOMS is coupled to the General Ocean Turbulence model (GOTM, Holt and Umlauf, 2008) and we use the $k-\varepsilon$ scheme with the stability functions derived from Canuto et al. (2001). The Liverpool Bay computational domain has a horizontal resolution of $\sim 180 \mathrm{~m}$ with 10 vertical sigma levels within the water column and is nested, in one-way, within a $1.8 \mathrm{~km}$ Irish Sea model (Fig. 2).

Both model domains are forced by $\sim 12 \mathrm{~km}$ hindcast atmospheric data from the UK Met Office numerical weather prediction model, the wind speed and air pressure is provided hourly, while the air temperature, specific humidity and cloud cover are provided 3 hourly. External conditions to the Irish Sea are provided hourly for the barotropic fields and daily for the baroclinic fields from the hindcast outputs of the pre-operational $\sim 12 \mathrm{~km}$ Atlantic Margin POLCOMS simulation, run at the NOC, Liverpool. Open boundary conditions for this model are provided by the Met Office Forecasting Ocean Assimilation Model (FOAM) system of the North Atlantic (Bell et al., 2000). Daily-mean river flow are obtained from the UK river archive (maintained by the Centre for Ecology and Hydrology) of the Environment Agency gaug- ing stations for the river systems in Liverpool Bay (Alyn, Bollin, Clwyd, Conwy, Dane, Dee, Douglas, Irwell, Lostock, Mersey, Ribble, Sankey Brook, Sinderland Brook, Weaver) and also provide the coastal freshwater source for the Irish Sea.

The Irish Sea model is run using the standard Charnock relation for wind stress, with a constant 0.0185 coefficient value and COARE bulk formulae to parameterise the other atmospheric drivers. This model provides hourly elevation and depth-averaged velocity components along with dailymean $(25 \mathrm{~h})$ depth-varying velocity, salinity and temperature components to force the boundaries of both local Liverpool Bay model experiments. The first experiment uses the full COARE bulk formulae and the second experiment replaces the wind stress parameterisation in the COARE bulk formulae with that of the standard Charnock relation. In neither of these numerical applications is the influence of surface wave age considered in calculating the surface roughness length.

Observations of the vertical velocity component profiles are available for this study period from three ADCPs, the locations of which are indicated in Fig. 2. Sites A and B are fixed nearshore moorings that were part of the Liverpool Bay Coastal Observatory (COBS, Howarth and Palmer, 2011), making measurements between 2002 and 2012. The Hilbre site was part of a series of Dee Estuary observational cruises (Bolaños and Souza, 2010) and was positioned in the Hilbre Channel, close to the estuary mouth, during the period 12:00, 14 February-09:00, 9 March 2008 (GMT). Having this set of estuarine observations to complement the coastal monitoring determined the period of this study. The velocity at the nearest ADCP bin to the surface (10\% of the depth below the surface) is used to validate the wind stress parameterisation within the model, the near surface being where the wind influence is the greatest. To do this the model data is extracted at a depth of $10 \%$ below the surface (i.e. the -0.1 sigma 
level). The surge elevation is obtained by applying harmonic tidal analysis to pressure sensor records and to the modelled total elevations at the same locations. The tidal analysis is performed using t-tide (Pawlowicz et al., 2002) with all the available shallow water constituents considered. The limited period ( $<1$ month of data) is likely to cause slight discrepancies between the analysed surge and that from the long-term tide gauge data (problems extracting the surge elevation are discussed further by Brown et al., 2012). For consistency, the same method has been applied to each location for both model and observation.

Wind observations are available from the COBS at Hilbre Island in the mouth of the Dee, a few hundred metres from the Hilbre Channel ADCP deployment. The long-term observed wind climate (Fig. 1a) shows local influence from the estuary causing a strong southeasterly wind contribution, in addition to more typical wind direction from the southwest to northwest (as observed offshore within the bay, see Wolf et al., 2010). For the period when observations were available for model validation the winds were dominated by southwesterly to westerly conditions (Fig. 1b). The $10 \mathrm{~m}$ winds at the Hilbre Island Met station were initially southeast and rarely in excess of $10 \mathrm{~m} \mathrm{~s}^{-1}$ (up to 21 February), before veering southwest and reaching speeds up to $20 \mathrm{~m} \mathrm{~s}^{-1}$. On 29 February, strong $(<23.6$ $\mathrm{m} \mathrm{s}^{-1}$ ) south-southwest winds veering west occurred over a $90 \mathrm{~h}$ period; such conditions are associated with extreme surge and wave generation in Liverpool Bay (Brown et al., 2011). The initial period is therefore considered calm and the later stormy. Waves within the estuary were below $0.61 \mathrm{~m}$ during the calm period, reaching $2.23 \mathrm{~m}$ during the stormy period. Offshore, the WaveNet wave rider buoy, close to Site A recorded wave heights reaching 0.63 and $4.83 \mathrm{~m}$ during these respective periods (available from the CEFAS WaveNet site, http://www.cefas.defra.gov.uk/our-science/ observing-and-modelling/monitoring-programmes/wavenet. aspx). The maximum surge of $1.32 \mathrm{~m}$ occurred on 29 February at 22:24GMT, recorded by the Liverpool Gladstone Dock tide gauge (available from the British Oceanographic Data Centre, www.bodc.ac.uk).

\subsection{Validation method}

Intercomparison between the two numerical experiments requires a quantitative assessment in order to determine which modelling approach is best. To that end, we introduce a timevarying comparative accuracy metric which is based on the absolute error of each model experiment. This metric is used to show the time variation in the comparison of the wind stress parameterisation performance. Using standard error metrics (RMS error and mean of the time-varying bias) applied to the full study period allows the overall accuracy of each model experiment to be determined. For each mooring location we determine the time-varying differential accuracy $(D A)$ as the difference between the absolute errors of each numerical experiment:

$D A_{i}=\left|O_{i}-C_{i}\right|-\left|O_{i}-B_{i}\right|$,

where $O$ represent observations, $C$ model results using the Charnock approach and $B$ model results using the COARE bulk formulae at each time instance, $i$. The time interval is hourly and the parameters considered are surge elevation, current speed and current direction. Here, the model error for the COARE bulk formulae set-up is subtracted from that of the standard Charnock relation set-up: a negative differential accuracy indicates better performance from the standard Charnock approach and a positive value indicates better performance of the COARE bulk formulae. This metric does not measure the magnitude of the accuracy (small or large), but compares the accuracy between modelling methods (a similar accuracy having a near zero value).

\section{Results}

\subsection{Time-varying accuracy}

The time-varying results of the differential accuracy metric (described above) are shown in Figs. 3-5 for each study site, along with the model wind forcing at that location. It is clearly seen in panel a (Figs. 3-5) that the Hilbre location is slightly sheltered from the wind and experiences lower speeds than the offshore sites. Across the domain the wind direction is fairly constant. In response to the atmospheric forcing, the surge (panel b), current speed (panel c) and current direction (panel d) all experience similar range in the variability of the differential accuracy metric at the three sites analysed. The closer the differential accuracy metric is to zero the smaller the difference between the accuracies of the two numerical experiments. It is seen that when one of the model set-ups performs better (i.e. if the line is negative or positive at that time) in one property, or at one location, it can still perform poorly (take the opposite sign) for another. At Site B the models perform with similar accuracy (small differential accuracy metric values) for surge. At all locations surge has the smoothest time-varying differential accuracy metric, showing the model experiments have a more consistent discrepancy in their accuracy for this property. The variability in the surge differential accuracy metric is greatest at the Hilbre location, suggesting very changeable agreement levels between the two experiments. The underlying trend at Hilbre is similar to that of Site A. This is most likely associated with the complexity of the surge elevation within the estuary system being generated locally while also being forced at the mouth by external (Site A) conditions (see Brown et al., 2012). For current speed and direction the time variation in the differential accuracy metric is much greater than for surge, due to the complex density-driven vertical structure in Liverpool Bay (Polton et al., 2011, 2013) and the Dee Estuary (Bolaños et al., 2013). There are periods when the models 

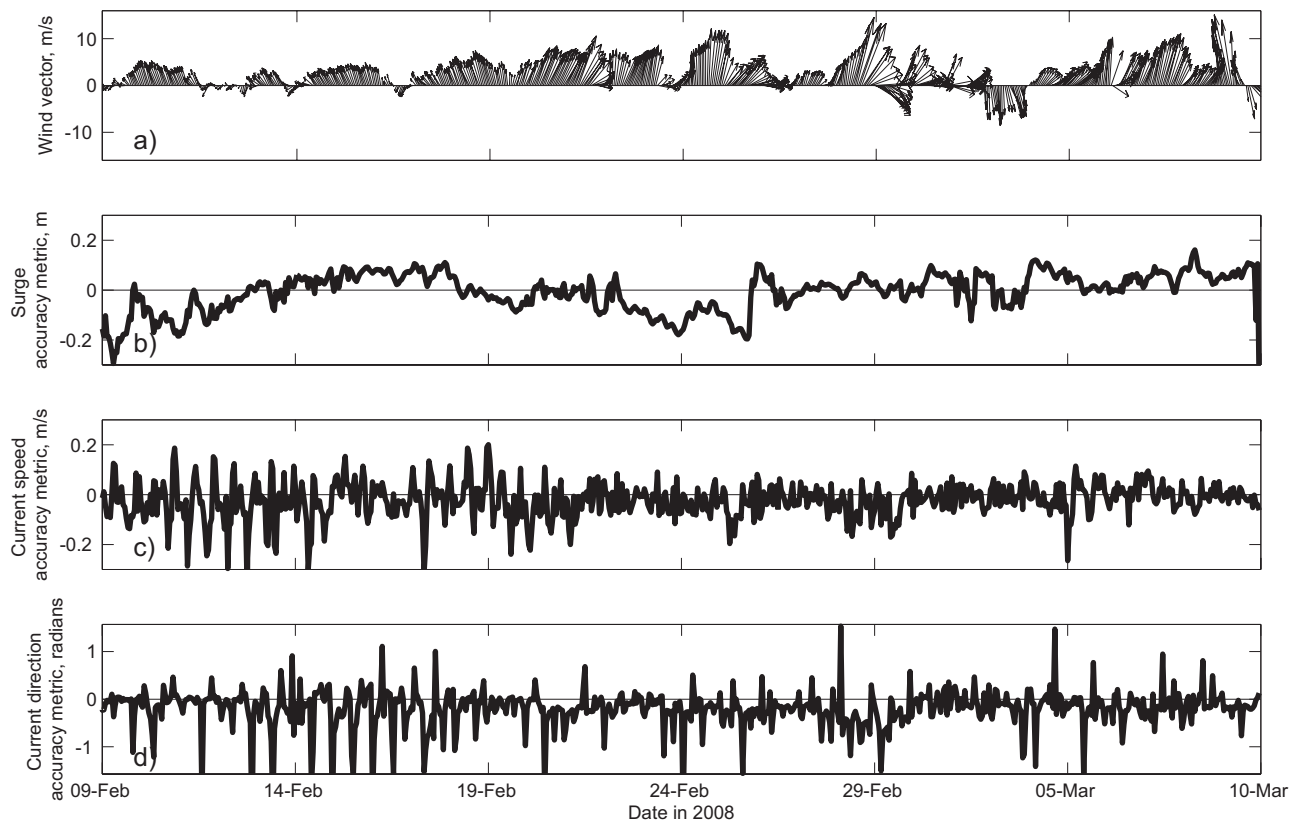

Fig. 3. Time-varying accuracy at Site A. (a) Wind vectors at this location and differential accuracy metric (DA) for (b) the surge, (c) the current speed and (d) the current direction. Negative values indicate the Charnock relation is performing with higher accuracy at this site than the COARE bulk wind stress formula and vice versa for positive values.
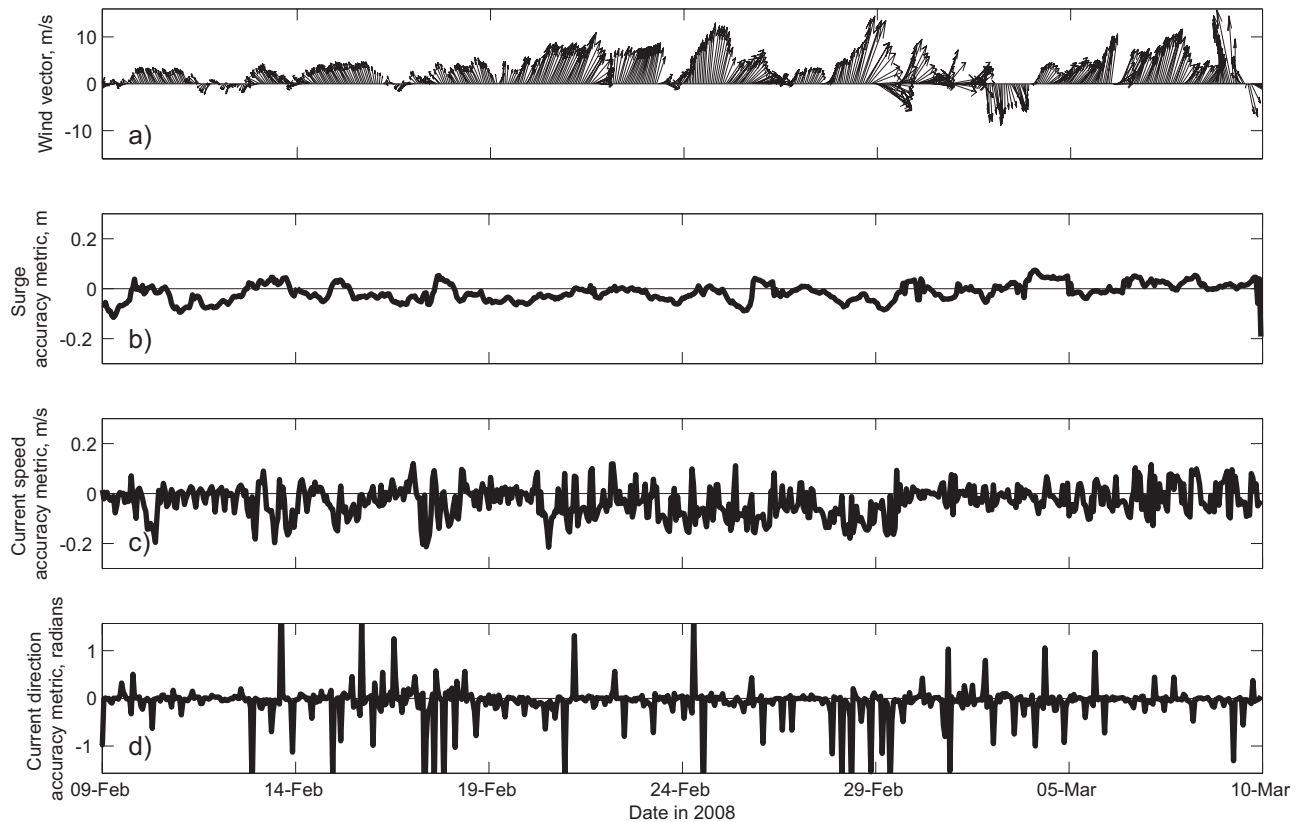

Fig. 4. Time-varying accuracy at Site B. (a) Wind vectors at this location and differential accuracy metric (DA) for (b) the surge, (c) the current speed and (d) the current direction. Negative values indicate the Charnock relation is performing with higher accuracy at this site than the COARE bulk wind stress formula and vice versa for positive values.

have similar (near zero $D A$ ) and noticeably different (spikes in $D A$ ) accuracy. The current speed and direction again show the wind stress parameterisations to be in closer agreement at Site B. This is a complementary finding to that of Polton et al. (2013), who show the shallower depth of Site A compared with Site B complicates the dynamics, causing less accuracy in model simulation at this location. The current speed shows most disagreement in model accuracy at Hilbre and the current direction shows most disagreement at Site A. For current direction, differences in the model accuracy often occur 

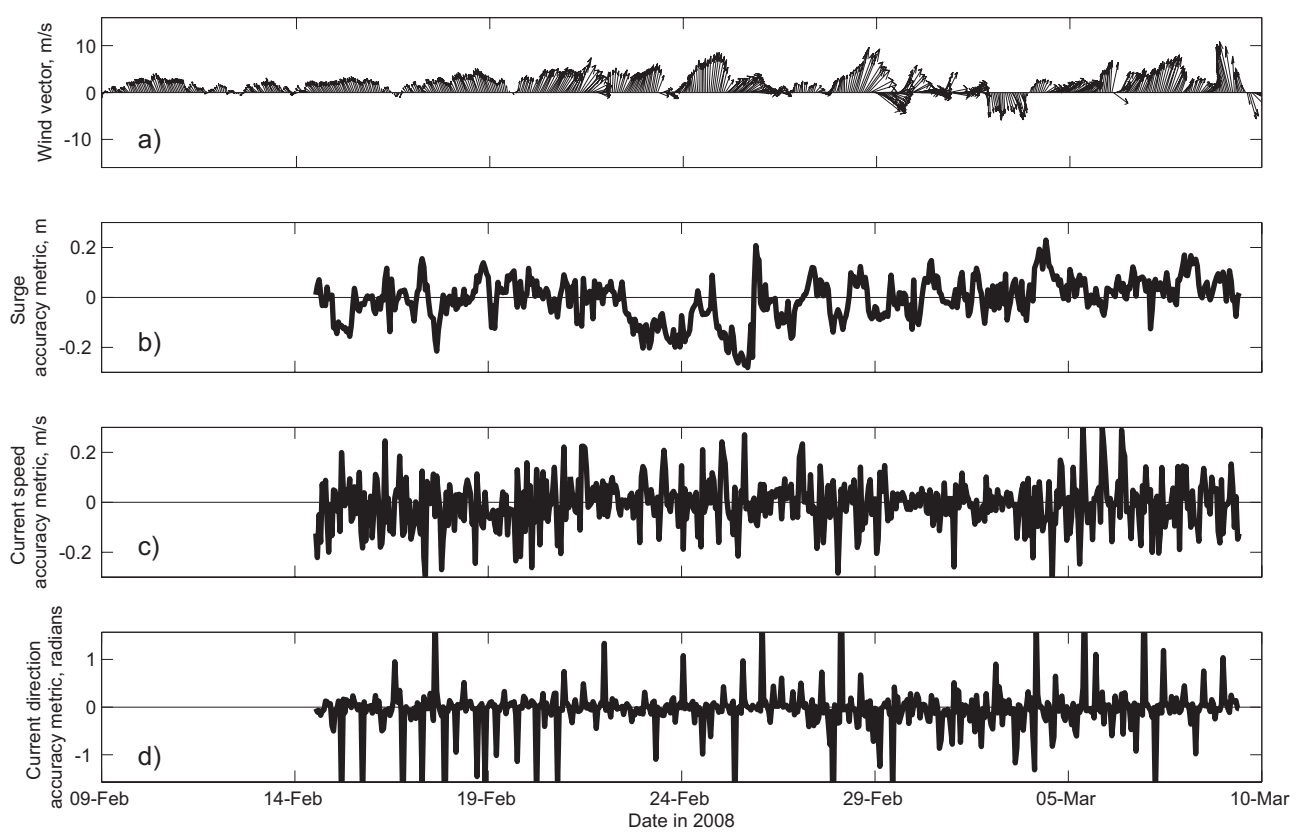

Fig. 5. Time-varying accuracy at the mooring location in the Hilbre Channel. (a) Wind vectors at this location and differential accuracy metric $(D A)$ for (b) the surge, (c) the current speed and (d) the current direction. Negative values indicate the Charnock relation is performing with higher accuracy at this site than the COARE bulk wind stress formula and vice versa for positive values.

close to slack water, which is expected as the weak currents are changing direction and this is when the model becomes least accurate.

No correlation between the wind direction and the better performing wind stress parameterisation is identified for any of the properties studied. The time-averaged differential accuracy metric (Table 1) clearly shows the Charnock method performances with slightly higher accuracy during this period of dominant southwest to west wind conditions. A $25 \mathrm{~h}$ period of northwest to northerly winds (starting at 19:00, 2 March GMT, Figs. 3-5) is selected to determine the performance of the modelling approaches during the less dominant wind directions, which provides a longer local fetch for Site B and Hilbre. During this short period, both models perform with higher accuracy at the offshore sites (smaller timevarying and time-averaged $D A$ values); and the Charnock method is still found to perform with slightly higher accuracy.

\subsection{Overall accuracy}

By calculating standard error metrics (RMS error, mean of the time-varying bias and the $R^{2}$ coefficient of determination) the overall accuracy of the Charnock and COARE bulk (Table 2) wind stress formulae can be identified for the study period. For the first two metrics a lower value indicates better performance, zero being perfect model agreement with observation. For the $R^{2}$ value 1 indicates perfect correlation. All parameters, with the exception of the current speed at the Hilbre mooring modelled using the Charnock approach, show a positive mean bias indicating model over-prediction. The current speed has the highest correlation coefficient, most likely due to the dominance of the tide.

The metrics for each property are quite similar across the 3 locations (Table 2). In most cases the current speed is the most accurately simulated property, followed by surge elevation, then current direction. The low values in all error metrics suggest either method can be considered to generate satisfactory results. However, in all cases the error over the time period is systematically greater for the COARE bulk formulae than for the standard Charnock relation, suggesting that the standard Charnock relation is the more accurate method for parameterising wind stress in coastal fetch limited conditions.

\section{Discussion with concluding statements}

Three locations within Liverpool Bay have been used to test the accuracy of two wind stress parameterisations within a coastal model: the COARE bulk formulae and the standard Charnock relation. The locations represent nearshore and estuarine environments. This study defines a time-varying differential accuracy metric, which is shown to be a simple, but effective method to compare model accuracy over time. Under these (very) fetch limited conditions, dominated by southwesterly to westerly winds, error analysis confirms both methods of wind stress parameterisation give valid results compared with ADCP and pressure sensor observations. A differential accuracy metric is applied to identify which 
Table 1. The mean values of the time-varying differential accuracy metric (DA, plotted in Figs. $3-5)$ for the full study period and a $25 \mathrm{~h}$ period of NW-W winds (starting at 19:00 GMT, 2 March 2008). Negative values indicate the Charnock relation is performing with higher accuracy at this site than the COARE bulk wind stress formula and vice versa for positive values. For zero values an extra degree of precision has been included in the bracketed value.

\begin{tabular}{lllll}
\hline Parameter & Error metric & Site A & Site B & Hilbre \\
\hline Surge elevation, m & Full period & -0.01 & -0.02 & -0.01 \\
& 25h NW-N & -0.02 & -0.01 & -0.01 \\
Current speed, $\mathrm{m} \mathrm{s}^{-1}$ & Full period & -0.02 & -0.03 & -0.01 \\
& $25 h N W-N$ & -0.01 & -0.02 & $-0.00(-0.001)$ \\
Current direction, degrees & Full period & -0.20 & -0.07 & -0.05 \\
& $25 h N W-N$ & -0.17 & -0.06 & -0.11 \\
\hline
\end{tabular}

Table 2. The validation metrics (RMS error, mean bias and $R^{2}$ ) showing the overall accuracy of the Charnock relation $(C)$ and the COARE bulk wind stress formula $(B)$ at the three study sites. For zero values an extra degree of precision has been included in the bracketed value. The value representative of higher accuracy is shown in bold type.

\begin{tabular}{lllll}
\hline Parameter & Error metric & Site A & Site B & Hilbre \\
\hline \multirow{3}{*}{ Surge elevation, $\mathrm{m}$} & RMS $C$ & 0.17 & $\mathbf{0 . 1 7}$ & $\mathbf{0 . 1 9}$ \\
& RMS $B$ & 0.17 & 0.18 & 0.20 \\
& Bias $C$ & $\mathbf{0 . 0 3}$ & $\mathbf{0 . 0 5}$ & $\mathbf{0 . 0 1}$ \\
& Bias $B$ & 0.05 & 0.07 & 0.04 \\
& $R^{2} C$ & $\mathbf{0 . 4 7}$ & $\mathbf{0 . 4 3}$ & $\mathbf{0 . 4 5}$ \\
& $R^{2} B$ & 0.42 & 0.37 & 0.37 \\
\hline \multirow{5}{*}{ Current speed, $\mathrm{m} \mathrm{s}^{-1}$} & RMS & $\mathbf{0 . 0 1}$ & $\mathbf{0 . 0 7}$ & $\mathbf{0 . 1 5}$ \\
& RMS $B$ & 0.13 & 0.11 & 0.16 \\
& Bias $C$ & $\mathbf{0 . 0 1}$ & $\mathbf{0 . 0 0}(0.001)$ & $-\mathbf{0 . 0 0}(-0.003)$ \\
& Bias $B$ & 0.03 & 0.01 & 0.03 \\
& $R^{2} C$ & $\mathbf{0 . 8 2}$ & $\mathbf{0 . 9 1}$ & $\mathbf{0 . 7 9}$ \\
& $R^{2} B$ & 0.72 & 0.80 & 0.76 \\
\hline \multirow{5}{*}{ Current direction, degrees } & RMS $B$ & $\mathbf{0 . 5 1}$ & $\mathbf{0 . 4 6}$ & $\mathbf{0 . 7 7}$ \\
& Bias $C$ & 0.71 & 0.58 & 0.83 \\
& Bias $B$ & $\mathbf{0 . 2 8}$ & $\mathbf{0 . 2 0}$ & $\mathbf{0 . 4 0}$ \\
& $R^{2} C$ & 0.48 & 0.27 & 0.45 \\
& $R^{2} B$ & $\mathbf{0 . 3 1}$ & $\mathbf{0 . 7 2}$ & 0.62 \\
& & 0.18 & 0.69 & 0.62 \\
\hline
\end{tabular}

method performs with highest accuracy in coastal seas. Over the duration of the study period either formula can perform more accurately at an instance, but on average over the longer term the standard Charnock relation performs with higher accuracy. A short $25 \mathrm{~h}$ period of northwesterly to northerly winds is focused on (Table 1) to represent the less dominant longer fetch wind directions during this study. This short period does suggest the standard Charnock relation with constant coefficient is still the more accurate to use.

The standard Charnock relation has a coefficient which is tuned for coastal surge application, while the COARE bulk formulae were developed for open ocean conditions using a variable Charnock coefficient. In this application the additional smooth surface roughness length (see Smith, 1988) is unlikely to have much influence in the COARE bulk formulae since wind speeds only occasionally dropped below
$3 \mathrm{~m} \mathrm{~s}^{-1}$ during the study. In Liverpool Bay the largest fetches are from west to northwest directions, but are still more limited than open ocean conditions. No correlation between the wind direction (fetch) and which model performs more accurately has been found. The standard Charnock coefficient has been set here to a value that gives good surge simulation across the eastern Irish Sea region. The value of this parameter is thought to be related to the model grid resolution $(0.0275$ for $\sim 12 \mathrm{~km}$ grid and 0.0185 for $\sim 1.8 \mathrm{~km}$ grid; Brown and Wolf, 2009). The lower setting for increased grid resolution (used here) is similar to the high wind setting applied in the COARE bulk formula. Adjustment to the value (0.0185) used here in the $180 \mathrm{~m}$ Liverpool Bay model has very little influence, as the model fetches are short and the model boundary conditions determine the majority of surge accuracy. For clarification, this coefficient has only 
been tuned for surge elevation and not circulation so this study also validates the accuracy of the Charnock relation on wind-driven circulation. The same boundary conditions (Charnock parameter 0.0185) have been used for each local model set-up in this case to test the two parameterisations at the local coastal scale.

In conclusion, it is found that the Charnock relation with a constant coefficient of 0.0185 performs favourably for both surge and near surface velocity (current speed and direction) over the longer term for this study location and wind conditions. These initial results now need to be extended to directly study the surface stress to remove uncertainty that could have been introduced by the modelling approach, such as the influence of bathymetry on the coastal circulation and surge propagation. Although both model experiments give valid results, it is advised that the standard Charnock wind stress relation with a constant coefficient of $\sim 0.0185$ in conjunction with the COARE bulk formulae for heat fluxes will give the highest accuracy over a period of study in (very) fetch limited coastal applications. Further study is required to more extensively test the robustness of this hypothesis at different coastal locations and under a full range of wind directions.

Acknowledgements. This research has been funded through the iCOASST: integrating coastal sediment systems (NERC grant NE/J005444/1), and ARCoES: Adaptation and Resilience of Coastal Energy Supply (EPSRC, ARCC-CN programme grant EP/I035390/1) projects. NERC core National Capability funding to the NOC is also acknowledged. Jane Williams (NOC) is thanked for providing the meteorological (wind and pressure) data, while Clare O'Neill (NOC, COBS) is thanked for providing the offshore temperature and salinity fields to the Irish Sea and supplementing the meteorological forcing with air temperature, humidity, and cloud cover to enable full atmospheric forcing. Tide gauge data were supplied by the British Oceanographic Data Centre as part of the function of the National Tidal \& Sea Level Facility, hosted by the National Oceanography Centre, Liverpool, and funded by the Environment Agency and Natural Environmental Research Council. Wave data were supplied by the Centre for Environment, Fisheries \& Aquaculture Science WaveNet monitoring programme. Coastal observations were provided by the Liverpool Bay Coastal Observatory at the Site A and B moorings in Liverpool Bay and the Dee Cruises provided observations within the Hilbre Channel.

Edited by: E. J. M. Delhez

\section{References}

Bell, M. J., Forbes, R. M., and Hines, A.: Assessment of the FOAM global data assimilation system for real-time operational ocean forecasting, J. Mar. Syst., 25, 1-25, 2000.

Bolaños, R. and Souza, A. J.: Measuring hydrodynamics and sediment transport processes in the Dee Estuary, Earth Sys. Sci. Data, $2,157-165,2010$.
Bolaños, R., Brown, J. M., Amoudry, L. O., and Souza, A. J.: Tides, river and wind influence on the circulation in a macrotidal estuary, J. Phys. Oceanogr., 41, 29-50, 2013.

Brown, J. M. and Wolf, J.: Coupled wave and surge modelling for the eastern Irish Sea and implications for model wind-stress, Cont. Shelf Res., 29, 1329-1342, 2009.

Brown, J. M., Bolaños, R., and Wolf, J.: Impact assessment of advanced coupling features in a tide-surge-wave model, POLCOMS-WAM, in a shallow water application, J. Mar. Sys., 87, 13-24, 2011.

Brown, J. M., Bolaños, R., Howarth, M. J., and Souza, A. J.: Extracting sea level residual in tidally dominated estuarine environments, Ocean Dynam., 62, 969-982, 2012.

Canuto, V. M., Howard, A., Cheng, Y., and Dubovikov, M. S.: Ocean turbulence. Part I: One-point closure model-momentum and heat vertical diffusivities, J. Phys. Oceanogr., 31, 1413-1426, 2001.

Charnock, H.: Wind-stress on a water surface, Q. J. Roy. Meteorol. Soc., 81, 639-640, 1955.

Fairall, C. W., Bradley, E. F., Hare, J. E., Grachev, A. A., and Edson, J. B.: Bulk parameterization of air-sea fluxes: updates and verification for the COARE algorithm, J. Clim., 16, 571-591, 2003.

Holt, J. T. and James, I. D.: An s coordinate density evolving model of the northwest European continental shelf: 1, model description and density structure, J. Geophys. Res., 106, 14015-14034, 2001.

Holt, J. and Proctor, R.: The seasonal circulation and volume transport on the northwest European continental shelf: a fine-resolution model study, J. Geophys. Res., 113, C06021, doi:10.1029/2006JC004034, 2008.

Howarth, M. J. and Palmer, M. R.: The Liverpool Bay Coastal Observatory, Ocean Dynam., 61, 1917-1926, 2011.

Janssen, P. A. E. M.: Quasi-linear theory of wind-wave generation applied to wave forecasting, J. Phys. Oceanogr., 21, 163-1642, 1991.

Kukulka, T. and Hara, T.: The effect of breaking waves on a coupled model of wind and ocean surface waves: I. Mature seas, J. Phys. Oceanogr., 38, 2145-2163, 2008.

Large, W. G., Morzel, J., and Crawford, G. B.: Accounting for surface wave distortion of the marine wind profile in low-level ocean storms wind measurements, J. Phys. Oceanogr., 25, 2959-2971, 1995.

Liu, B., Liu, H., Xie, L., Guan, C., and Zhao, D.: A Coupled Atmosphere-Wave-Ocean Modeling System: Simulation of the Intensity of an Idealized Tropical Cyclone, Mon. Weather Rev., 139, 132-152, 2011.

Mastenbroek, C., Burgers, G., and Janssen, P. A. E. M.: The dynamical coupling of a wave model and a storm surge model through the atmospheric boundary layer, J. Phys. Oceanogr., 23, 18561866, 1993.

Moon, I.-J.: Impact of a coupled ocean wave-tide-circulation system on coastal modelling, Ocean Modell., 8, 203-236, 2005.

Neelin, J. D., Latif, M., and Jin, F.-F.: Dynamics of coupled ocean-atmosphere models: the tropical problem, Ann. Rev. Fluid Mech., 26, 617-659, 1994.

O’Neill, C. K., Polton, J. A., Holt, J. T., and O'Dea, E. J.: Modelling temperature and salinity in Liverpool Bay and the Irish Sea: sensitivity to model type and surface forcing, Ocean Sci., 8, 
903-913, doi:10.5194/os-8-903-2012, 2012.

Pawlowicz, R., Beardsley, B., and Lentz, S.: Classical tidal harmonic analysis including error estimates in MATLAB using T_TIDE, Comp. Geosci., 28, 929-937, 2002.

Polton, J. T., Palmer, M. R., and Howarth, M. J.: Physical and dynamical oceanography of Liverpool Bay, Ocean Dynam., 61, 1421-1439, 2011.

Polton, J. T., Palmer, M. R., and Howarth, M. J.: The vertical structure of time-mean estuarine circulation in a shallow, rotating, semi-enclosed coastal bay: A Liverpool Bay case study with application for monitoring, submitted to Cont. Shelf Res., 59, 115126, 2013.
Smith, S. D.: Coefficients for sea surface wind stress, heat flux, and wind profiles as a function of wind speed and temperature, J. Geophys. Res., 93, 15467-15472, 1988.

Umlauf, L., Burchard, H., and Bolding, K.: General ocean turbulence model: source code documentation, Technical Report 63, Baltic Sea Research Institute Warnemünde, Warnemünde, 346 pp., 2005.

Verspecht, F., Rippeth, T. P., Howarth, M. J., Souza, A. J., Simpson, J. H., and Burchard, H.: Processes impacting on stratification in a region of freshwater influence: application to Liverpool Bay, J. Geophys. Res., 114, C11022, doi:10.1029/2009JC005475, 2009.

Wolf, J., Brown, J. M., and Howarth, M. J.: The wave climate of Liverpool Bay - observations and modelling, Ocean Dynam., 61, 639-655, 2011. 